\title{
Maximum Power Point Tracking Using Fuzzy Logic Control in Constant Voltage for Different Environmental Conditions
}

\author{
R. Shalaby ${ }^{1}$, M. Shabaan ${ }^{2}$, B. Abuzalam ${ }^{1}$, M.A.Younes. ${ }^{2}$ \\ ${ }^{I}$ The Faculty of Electronic Engineering, El Menoufia, Egypt \\ ${ }^{2}$ National Water Research Center, Cairo, Egypt
}

\begin{abstract}
Maximum power point tracking (MPPT) is a real problem in harvesting power of photovoltaic (PV) solar cells. Constant voltage method (CV) has been used to get MPP. Unfortunately, to determine the reference maximum voltage in $C V$ method, the photovoltaic module should be regularly disconnected to-measure the open circuit voltage and calculate the new operating point; this causes power loosing rather than time consuming. This paper introduces a fully electronic system that automatically generates a reference maximum voltage which allows the PV modules to produce all the power they are capable of. Unlike the approximated calculations of reference values of traditional $C V$; the charge of this accurate reference-generator is to generate an expected operating point over wide range of weather variations without disconnecting the PV modules. A T-S based fuzzy logic controller has been utilized to calculate the maximum operating voltage $\left(V_{m p p}\right)$ of the $P V$ module according to weather variations i.e. temperature and irradiation.
\end{abstract}

Keywords: Constant Voltage; Photovoltaic module; MPPT and Automatic $V_{\text {mpp }}$ generation

\section{Introduction}

The photovoltaic energy is increasing interest in electrical power applications. It is crucial to operate PV energy conversion systems near maximum power point to increase the output efficiency of PV. However, the nonlinear nature of PV systems is apparent from Figure. 1. i.e. the current and power of PV array depend on the array terminal operating voltage. In addition, the maximum power operating point is changing with Irradiation level and temperature. Therefore, the tracking control of maximum power point is a complicated problem. To overcome these problems, many tracking control strategies have been proposed such as perturb and observe $(\mathrm{P} \& \mathrm{O})$ which depends on increasing or decreasing a step of power. However when the environment condition changes rapidly, a fast decision of a step change is important since the MPP tracking velocity is delayed as discussed in[1][2]. In [3] the incremental conductance that needs high effectiveness CPU due to many computational complexities and it increases the system unit cost was discussed. The constant

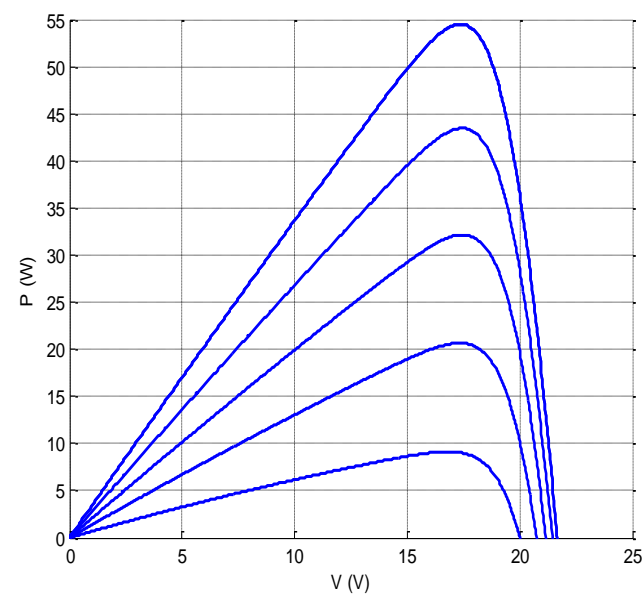

(a)

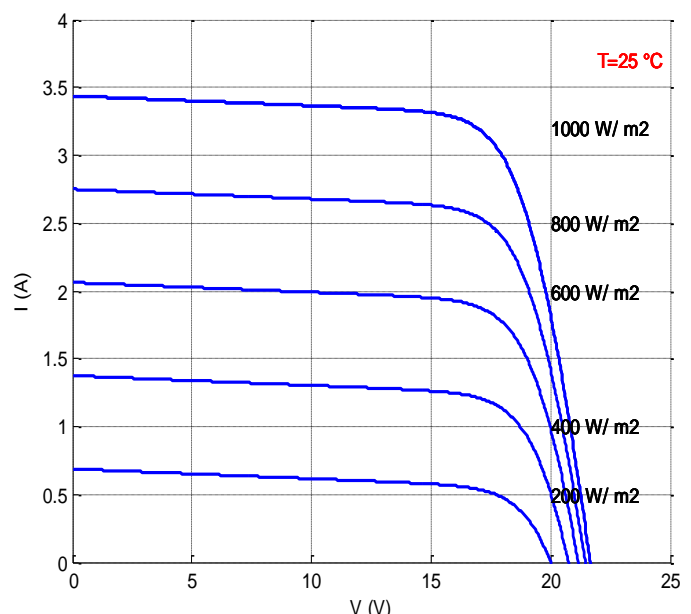

(b)

Figure 1 PV characteristics (a) Current vs. voltage (b) Power vs. voltage

Voltage assumes that individual Irradiation and temperature variations on the array are insignificant, and that the constant reference voltage is an adequate approximation of the true MPP. Operation is therefore never exactly at the MPP and different data has to be collected for different geographical regions as [4] pointed. Artificial neural network (ANN) methods employ back-propagation (BP) training algorithm. Larger number of hidden nodes yield more accurate results, but at the expense of longer computational time. Hence, in rapid fluctuations of environment, the ANN MPPT may not be able to respond quickly enough to cope with the fast 
changes as in [5][6]. the fuzzy logic control which depends a lot on the knowledge of the user or control engineer in choosing the right error computation and coming up with the rule base table has been discussed in [7][8]. All These challenges made it crucially to modify simple and low cost method as constant voltage method.

\section{Constant Voltage Method}

The Constant Voltage algorithm is the simplest MPPT control method. The operating point of the PV array is kept near the MPP by regulating the array voltage and matching it to a fixed reference voltage ( $V_{\text {ref }}$ )equal to the $\mathrm{V}_{\mathrm{mpp}}$ of the characteristic PV module or another pre-valuated best voltage value [9]. The CV method assumes that Irradiation and temperature variations on the array are insignificant on the $V_{m p p}$, and that the constant reference voltage $V_{\text {ref }}$ is an adequate approximation of the real MPP. Therefore, the operating point is never exactly at the MPP and different data have to be adopted for different geographical regions. The CV method needs the measurement of the PV array voltage $V_{p v}$ in order to set up the duty-cycle (D) of the DC/DC converter. It is important to observe that when the PV panel is in low Irradiation conditions the CV technique is generally more effective than either the P\&O method or the IC method [10]. The CV control method has the disadvantage that it is unable to track the MPP in rapidly changed solar irradiation so that the power efficiency is reduced. However, there is the advantage of reducing the sensor of an array. There is a near linear relationship between maximum voltage and open circuit voltage $\left(V_{o c}\right)$ of the cell which is described by the equation:

$V_{m p p} \approx \mathrm{K} V_{o c}$

Where $\mathrm{k}$ is a constant ranged from 0.71 and 0.78 . Firstly $\mathrm{k}$ can be computed by measuring $V_{m p p}$ and measure $V_{o c}$ then calculate $\mathrm{k}$ from the above relation.by repeating this procedure and take the average of all $\mathrm{k}$ values as in [11], then $V_{O C}$ can be measured periodically by disconnecting the load regularly. But this method will make a power loss. [12] proposed a solution for this problem by connecting PV pilot cell in parallel with the main PV module and that PV pilot has the same characteristics of the main module, momentarily the pilot cell is swept and $V_{o c}$ is measured without losing the power.[13] were introduced a new solution using neural networks and genetic algorithm to get $V_{m p p}$ based on irradiation and temperature but this method is time consuming and need a high effectiveness CPU due to many computational complexities and it increases the system unit cost. Another drawback in this method is that the relationship that describes $V_{m p p}$ an approximation of the real value so it won't ever reach the maximum power point but it will be close to it as in [10] .since environmental variations have a clear effect on voltage in special and on PV characteristics in general, Fuzzy logic controller (FLC) have been introduced to calculate the exact maximum voltage point. Consequently exact maximum power point can be obtained based on the environmental variations and the nonlinear characteristics of PV cells. A FLC is applied to generating a maximum possible voltage $\left(V_{m p p}\right)$ of PV modules which is corresponding to the maximum obtainable power point. The proposed FLC take the weather conditions into account through the application of temperature and Irradiation as fuzzy inputs.

\section{System Structure}

Figure 2 is showing the simple structure of the proposed constant voltage method. It consists of PV panel, buck DC-DC converter and proportional-integral (PI) which is responsible for controlling the duty cycle of the converter where reference voltage of PI controller is the output of FLC. $V_{m p p}$ is the desired point of the PV module which can be acquired by watching the system , and the load is a resistor. The PV module that was used here is Solar moduleSM55, its technical characteristics at standard test condition is shown in Table 1.

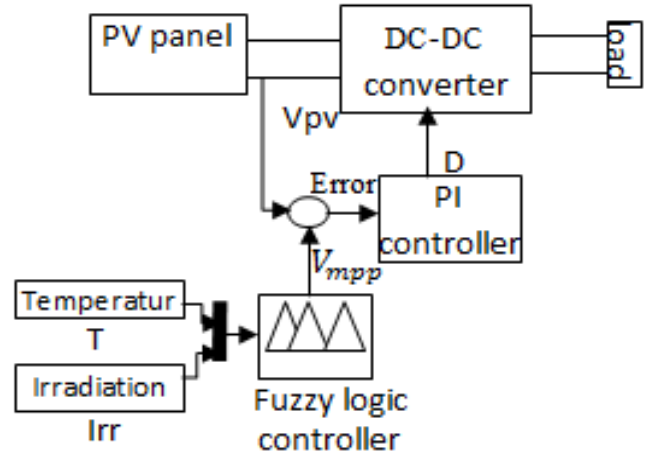

Figure 2 system structure containing the proposed method 


\section{Fuzzy Logic Controller Design}

Fuzzy inference system (FIS) contains the following stages: fuzzification interface, a rule base, a database, a decision-making unit, and finally a defuzzification interface. A FIS with five functional block described in Figure 3. The function of each block is as follows:

- Rule base containing a number of fuzzy rules (IF-THEN rules).

- Database defines the membership functions of the utilized fuzzy sets.

- The decision-making unit performs the inference operations on the rules

- The fuzzification interface is transforming the crisp input values into degrees of match with linguistic values

- Unlike fuzzification, the defuzzification interface is transforming the fuzzy values resulting from the inference engine into a crisp output.

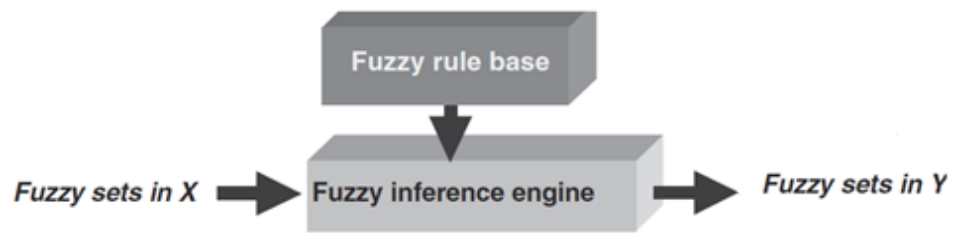

Figure 3 structure of fuzzy logic control

Table 1 Parameters of the solar array Solar moduleSM55 $25^{\circ} \mathrm{C}, 1000 \mathrm{~W} / \mathrm{m} 2$.

\begin{tabular}{|l|l|}
\hline Characteristics & SMF5 \\
\hline Number of cells in series & 36 \\
\hline Number of cells in parallel & 1 \\
\hline Maximum Power (Pmax) in watt & 55 \\
\hline Open Circuit Voltage (Voc) & $21.7 \mathrm{~V}$ \\
\hline Short-circuit Current (Isc) & $3.45 \mathrm{~A}$ \\
\hline Maximum power point Voltage (V-m) & $17.4 \mathrm{~V}$ \\
\hline Maximum power point Current (Imax) & $3.15 \mathrm{~A}$ \\
\hline Temperature Coefficient of Voc & $-.077 \mathrm{~V} /{ }^{\circ} \mathrm{C}$ \\
\hline Temperature Coefficient of Isc & $1.2 \mathrm{~mA} /{ }^{\circ} \mathrm{C}$ \\
\hline
\end{tabular}

In this system a linear change in $V_{m p p}$ (the output of FLC) has been noticed so Takagi-Sugeno FLC is preferred here to get accurate and easy calculations.

\subsection{Fuzzification}

Temperature and Irradiation the inputs of this system are converted from crisp values to fuzzy values in this phase represented in membership functions in Fig. 5.

\subsection{Fuzzy Inference Engine}

This phase provide the system with the suitable control rule that governs this operation using rule table which define the relationship between inputs

and output using "IF ... Then" rules as depicted in figure 4.

For example: Rule 1:

If Input $_{1}=x$ and Input $_{2}=y$, then

Output is $Z=a x+b y+c$.

The output level $Z_{i}$ of each rule is weighted by the firing strength $w_{i}$ of the rule. For example, for an AND rule with Input $1=x$ and Input $2=y$, the firing strength is

$$
\mathrm{w}_{\mathrm{i}}=\operatorname{AND}\left(\mathrm{F}_{1}(\mathrm{x}), \mathrm{F}_{2}(\mathrm{y})\right)
$$

Where $\mathrm{F}_{1,2}(\cdot)$ are the membership functions for Inputs 1 and 2 . The final output of the system is the weighted average of all rule outputs. Five Fuzzy sets describing irradiation [Very Small (VS), Small(S), Medium (M), Big (B) and Very Big (VB)], and Temperature [Low (L), Medium (M), Normal (N), Upper Normal and High $(\mathrm{H})]$ were proposed as shown in Table 2, 


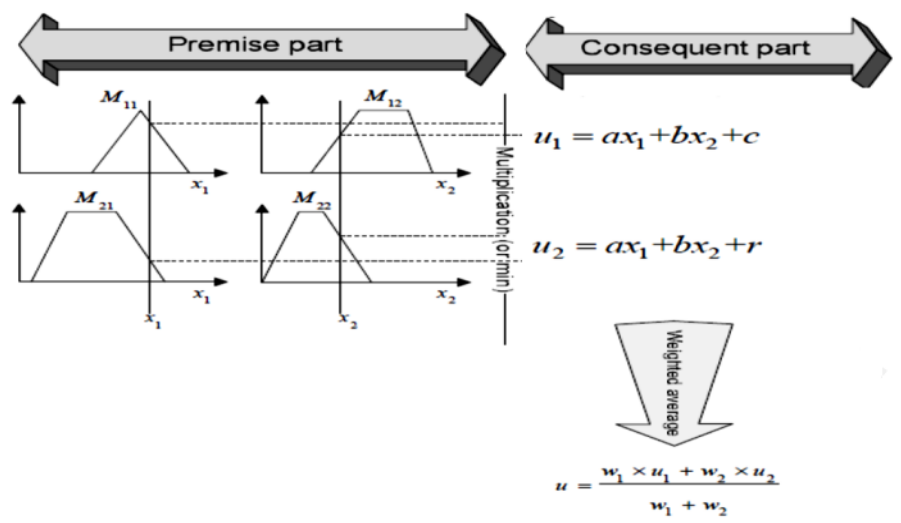

Figure 4 Fuzzy logic Incident and consequent diagram

According to Takagi-Sugeno a linear relations in the consequences enabled us to control this highly nonlinear system as in [14]. The output $V_{m p p}$ is described by the relation $V_{m p p}=\mathrm{ax}+\mathrm{c}$ where $\mathrm{x}$ is the temperature and irradiation and a, c are constants. The voltage $V_{m p p}$ is highly depending on temperature.

\subsection{Defuzzification}

\section{Table 2 Fuzzy rules}

In this phase the output is a fuzzy value it has to be converted into crisp or real value to be used in calculation, many methods were used for defuzzification for Sugeno-style inference, wtaver (weighted average) or wtsum (weighted sum). Weighted average, with the following equation, has been used.

Final output $=\frac{\sum_{1}^{\mathrm{N}} \mathrm{z}_{\mathrm{i}}}{\sum_{1}^{\mathrm{N}} \mathrm{w}_{\mathrm{i}}}$

Where $\mathrm{N}$ is the number of rules, $\mathrm{z}_{\mathrm{i}}$ is the output level, $\mathrm{w}_{\mathrm{i}}$ is firing

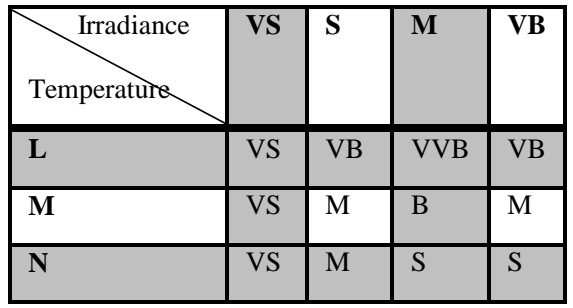
strength of the rule

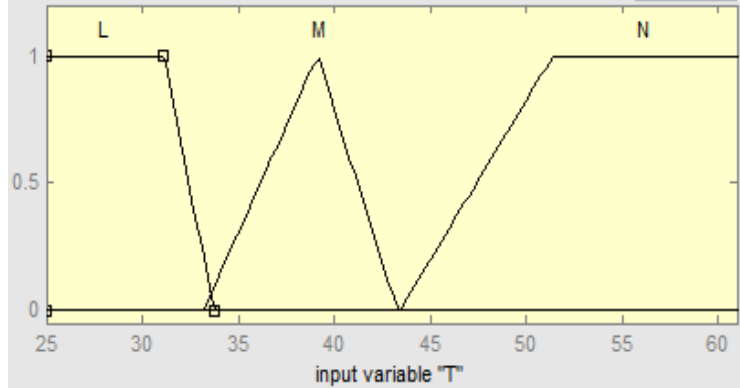

(a)

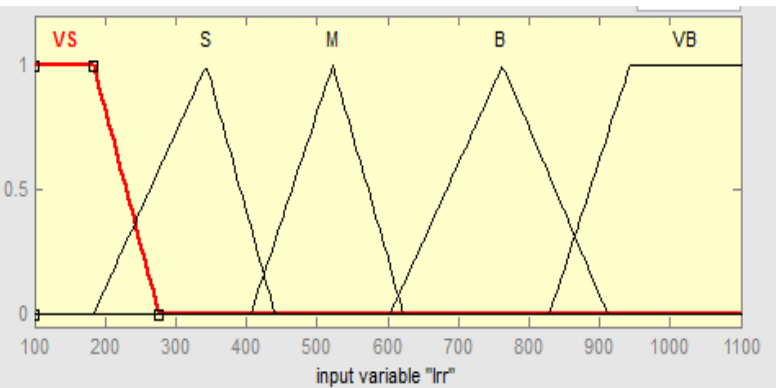

(b)

Figure 5. (a) Membership function of temperature (T) and (b) Membership function of Irradiation ( $\left.I_{\mathrm{rr}}\right)$

\section{Simulation Results}

Data sets for voltage and power covering a large range were aimed to be obtained to ensure operation of MPPT controller for a wide range of environmental conditions. Our proposed controller has proved its proficiency in tracking maximum power point .The dataset used to cover the range between 200 and 1000W/ $\mathrm{m}^{2}$, i.e. [200, 400, 600, 800, and 1000] for irradiation, and between 25 and $55^{\circ} \mathrm{C}$ for cell temperature as depicted in figures 6,7 .

For the given environmental conditions (different irradiation and temperature values), in figure 6 , irradiance levels were increased in a sudden steps manner from $200 \mathrm{~W} / \mathrm{m}^{2}$ up to $1000 \mathrm{~W} / \mathrm{m}^{2}$ and then decreased again. Results show the capability of the introduced fuzzy logic controller to harvest the maximum possible power of a photovoltaic module. Difference between figures (a) and (b) of different temperature is very clear.

Figure 7 shows the ability of the proposed FLC to generate a reference value of the possible maximum cell voltage $\left(\mathrm{V}_{\mathrm{mpp}}\right)$ at which the PV module can generate its maximum power. Values of $\mathrm{V}_{\mathrm{mpp}}$ at 600,800 , and 1000 $\mathrm{W} / \mathrm{m}^{2}$ is very close to each other. 


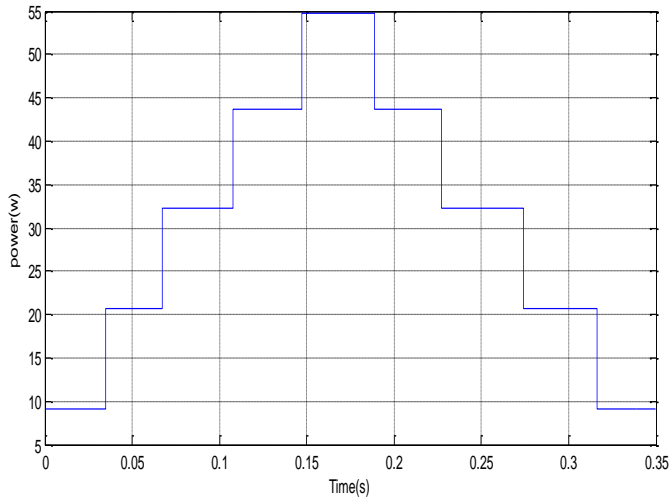

(a)

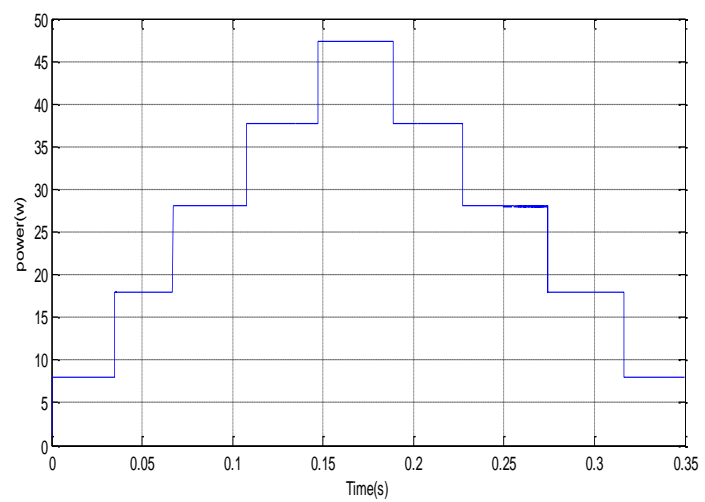

(b)

Figure 6 Maximum power gained for different irradiation at (a) $\mathrm{T}=25^{\circ} \mathrm{C} \quad$ (b) $\mathrm{T}=55^{\circ} \mathrm{C}$

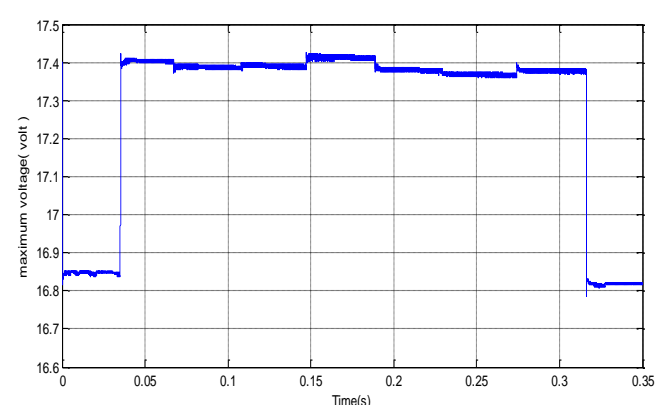

(a)

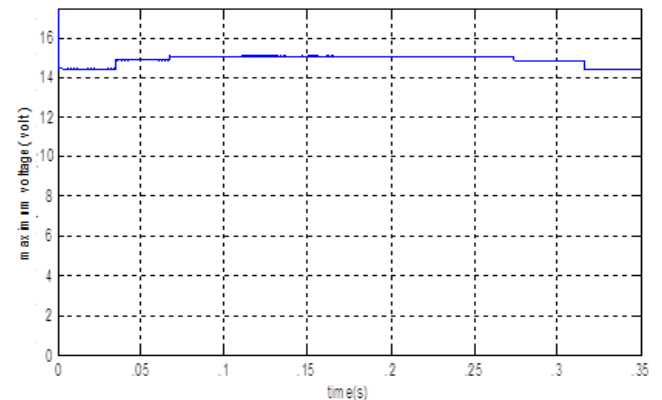

(b)

Figure $7 \mathrm{~V}_{\mathrm{mpp}}$ is following different irradiation at different levels at: (a) $\mathrm{T}=25^{\circ} \mathrm{C}$ and $(\mathrm{b}) \mathrm{T}=55^{\circ} \mathrm{C}$

Voltage at these irradiance levels may appear constant but it isn't because of its characteristics as it is clear on the characteristic curve in figure 1 Fast and accurate tracking of maximum power was achieved.

\section{Conclusions}

In this paper improvements have been added to the constant voltage method to track maximum power point in photovoltaic cells. In traditional method the load had to be regularly disconnected to measure $\mathrm{V}_{\mathrm{oc}}$, and a PV pilot cell was connected with the main module. Periodically, the pilot cell is swept and $\mathrm{V}_{\mathrm{oc}}$ is measured. The proposed method applied fuzzy logic control to treat with the variation of temperature and irradiation which dramatically affect $\mathrm{V}_{\mathrm{mpp}}$ of PV modules. The proposed Fuzzy logic controller shows its capability to instantaneously generate a desired reference for the maximum voltage according to the environmental variations (c.f. figure 7). Simulation results show also a good capability to track the maximum power point, which make it possible to avoid most of the drawbacks related to the application of traditional tracking strategies when weather conditions changes. The results have proved proficiency of the proposed method in tracking the maximum voltage point in different environmental conditions.

\section{References}

[1]. C.Hua and C. Shen "Comparative Study of Peak Power Tracking Techniques for Solar Storage System", Vol. 2, Pp.679-683,1988. IEEE Applied Power Electronics Conference and Exposition Proceedings.

[2]. Hussein, K.H., I. Muta, T. Hoshino and M. Osakada (1995). "Maximum Photovoltaic Power Tracking: An Algorithm for Rapidly Changing Atmospheric Conditions", Vol. 142, No. 1, Pp. 59-64, IEE Proceedings on Generation, Transmission and Distribution.

[3]. A.Brambilla"New Approach to Photovoltaic Arrays Maximum Power Point Tracking", Vol. 2, Pp. 632-637,1998, Proceeding of 30th IEEE Power Electronics Specialists Conference.

[4]. W. Swiegers and J.H.R. Enslin."An Integrated Maximum Power Point Tracker for Photovoltaic Panels", Vol. 1, Pp. 40-44, ,jul 1998.Proceedings of IEEE International Symposium on Industrial Electronic.

[5]. T.Hiyama, and K. Kitabayashi"Neural Network Based Estimation of Maximum Power Generation from PV Module Using Environment Information", Vol. 12, No. 3, Pp. 241-247,Sep 1997. IEEE Transactions on Energy Conversion.

[6]. A.Al-Amoudi, and L. Zhang "Application of Radial Basis Function Networks For Solar-Array Modeling and Maximum PowerPoint Prediction", Vol. 147, No.5, Pp. 310-316,2000. IEE Proceeding-Generation, Transmission and Distribution.

[7]. C.Y.,Won, D.H. Kim, S.C. Kim, W.S. Kim and H.S. Kim . "A New Maximum Power Point Tracker of Photovoltaic Arrays Using Fuzzy Controller", Vol. 1, Pp. 396-403,1994.Proceeding of Annual IEEE Power Electronics Specialists Conference, PESC.

[8]. A. H.Mahmoud, M. Mashaly, S. A. Kandil, H. El Khashab, and M.N.F. Nashed."Fuzzy Logic Implementation for Photovoltaic Maximum Power Tracking", Vol. 1, Pp. 155-160,2000.Proceedings 9th IEEE International Workshop on Robot and Human Interactive Communication. 
[9]. Kang, Sung-Jun, Jae-Sub Ko, Jung-Sik Choi , Mi-Geum Jang, Ju-HuiMun , Jin-Gook Leeand Dong-Hwa Chung"A Novel MPPT Control of photovoltaic system using FLC algorithm", Vol. 1, Pp. 434-439,2011.International Conference Control Automation and Systems (ICCAS), Gyeonggi-do.

[10]. F.,Roberto, S. Leva. "Energy comparison of MPPT techniques for PV Systems" ,Vol. 3, Pp. 446-455,2008. Wseas Transactions on power systems.

[11]. T.Esram and L. Chapman (2007)."Comparison of Photovoltaic Array Maximum Power Point Tracking Techniques",Vol. 22, Pp. 439-449, Energy Conversion, IEEE Transactions.

[12]. A.Tariq M. S. Jamil ."Development of analog maximum power point tracker for photovoltaic panel", Vol. 1, Pp. 251-255,2005. Proceedings of IEEE International Conference on Power Electronic Drive Systems, PEDS.

[13]. A.Kulaksız, A.,RamazanAkkaya . "A genetic algorithm optimized ANN-based MPPT algorithm for a stand-alone PV system with induction motor drive", Vol. 86, Pp. 2366-2375,2012.Elsevier solar energy.

[14]. T.Takagi, M. Sugeno . "Identification of systems and its applications to modeling and control", Vol. 1, Pp. 116-132,1985,Man and Cybernetics, IEEE Transactions on Systems. 